\title{
The diversities in thyroid cytopathology practices among Asian countries using the Bethesda system for reporting thyroid cytopathology
}

\author{
Truong Phan Xuan Nguyen ${ }^{1}$, Vien Thanh Truong ${ }^{2}$, Kennichi Kakudo ${ }^{3}$, Huy Gia Vuong ${ }^{4,5}$ \\ ${ }^{1}$ Department of Pathology, Cho Ray Hospital, Ho Chi Minh City, Vietnam; ${ }^{2}$ Department of Cardiology, The Christ Hospital Health Network, \\ Cincinnati, OH, USA; ${ }^{3}$ Department of Pathology and Thyroid Disease Center, Izumi City General Hospital, Izumi-city, Japan; ${ }^{4}$ Department of \\ Pathology, ${ }^{5}$ Stephenson Cancer Center, Oklahoma University Health Sciences Center, Oklahoma City, OK, USA \\ Contributions: (I) Conception and design: HG Vuong, K Kakudo; (II) Administrative support: HG Vuong; (III) Provision of study materials or \\ patients: All authors; (IV) Collection and assembly of data: All authors; (V) Data analysis and interpretation: All authors; (VI) Manuscript writing: All \\ authors; (VII) Final approval of manuscript: All authors. \\ Correspondence to: Huy Gia Vuong, MD, PhD. Department of Pathology, Oklahoma University Health Sciences Center, Oklahoma City, OK 73104, \\ USA; Stephenson Cancer Center, Oklahoma University Health Sciences Center, Oklahoma City, OK 73104, USA. Email: huyvuong@hotmail.com.
}

Background: The Bethesda System for Reporting Thyroid Cytopathology (TBSRTC) has been adopted and widely used among Asian countries. This study aims to investigate the application of TBSRTC in thyroid cytology practice among Asian countries

Methods: We searched electronic databases including PubMed and Web of Science from 2010 to 2019. Meta-analysis of proportion and their $95 \%$ confidence intervals (CIs) were calculated using the randomeffect model. Meta-regression and subgroup analysis were used to search for heterogeneity origins.

Results: We included 42 Asian studies with 84.953 fine-needle aspirations. Among six categories, benign was the most commonly diagnosed category. The resection rate (RR) and risk of malignancy (ROM) were highest in malignant and SM categories, and lowest among benign nodules. Thyroid cytology practice in Asia was characterized by a low RR and high ROM in patients with indeterminate thyroid nodules. There was a significant amount of heterogeneities of TBSRTC outputs (frequency, resection rate, and malignancy risk) among Asian countries. Meta-regression showed that the sources of heterogeneity might stem from the differences in study origin and the application of molecular testing. We highlighted the usefulness of preoperative molecular testing to select patients for surgery.

Conclusions: Our study provided insight regarding thyroid cytology practice among Asian countries. Active surveillance is commonly used in Asian practice resulting in a low RR and high ROM for indeterminate nodules. There are still variations in general thyroid cytology practice in Asia. Future guidelines and consensus regarding the application of TBSRTC in thyroid cytology practice among Asian countries are required.

Keywords: The Bethesda System for Reporting Thyroid Cytopathology (TBSRTC); fine-needle aspiration (FNA); cytology; thyroid; risk of malignancy (ROM); resection rate; Asia

Submitted Mar 25, 2020. Accepted for publication Jun 22, 2020.

doi: 10.21037 /gs-20-404

View this article at: http://dx.doi.org/10.21037/gs-20-404 


\section{Introduction}

The fine-needle aspiration (FNA) is an accurate, cost-effective, minimally invasive procedure in the management of thyroid nodules and helpful in tailoring therapeutic decisions (1). Currently, the Bethesda System for Reporting Thyroid Cytopathology (TBSRTC) is established to provide uniform terminology and criteria for the diagnosis of thyroid nodules and guide the clinical treatment. TBSRTC includes six categories including nondiagnostic (ND), benign, atypia of undetermined significance/follicular lesion of undetermined significance (AUS/FLUS), follicular neoplasm/suspicious for follicular neoplasm (FN/SFN), suspicious for malignancy (SM), and malignant $(2,3)$.

TBSRTC was designed and originated from the USA, but it has been widely adopted in many European and Asian countries (4). We recently found that Asian cohorts had a significantly higher risk of malignancy (ROM) than Western series in most of TBSRTC categories (4). However, a huge amount of heterogeneity was found among countries (4).

This study aims to focus on the application of TBSRTC in cytopathology practice among Asian countries and to explain any sources of heterogeneity if present. We present the following article in accordance with the PRISMA reporting checklist (available at http://dx.doi.org/10.21037/ gs-20-404.)

\section{Methods}

\section{Search strategy and identification of target studies}

Potential articles were searched in PubMed and Web of Science from 2010 to 2019 using the keywords "Bethesda AND thyroid". Our study protocol generally followed the recommendation of the Preferred Reporting Items for Systematic Review and Meta-analysis (PRISMA) statement (5).

\section{Selection criteria and abstract screening}

All searched results were imported into Endnote. Two reviewers screened the titles and abstracts using the following inclusion criteria: (I) studies reporting of thyroid FNA results utilizing TBSRTC; (II) data must include the number of FNAs, the number of cases undergoing resection, number of malignancies following surgery in at least one of six TBSRTC categories; and (III) the studies were performed in Asian populations. The exclusion criteria were: (I) studies did not meet all of the above inclusion criteria; (II) reviews; (III) conference papers, proceedings, theses; and (IV) studies focusing only on pediatric population. If there were any discrepancies between 2 reviewers, discussion and consensus were reached.

\section{Full-text screening and data extraction}

Two reviewers screened the full-text of potential articles and extracted data into a predefined data extraction form. Any discrepancies were resolved by discussion and consensus. The extraction information includes study title, year, journal, institution, city, country, year of publication, study design (prospective or retrospective), number of patients, age, sex, proportion of ultrasound-guided FNAs, and number of FNAs, surgeries, and cancers for each TBSRTC category.

\section{Data analysis}

The frequency of thyroid FNA samples is calculated by dividing the number of cases in each TBSRTC category by the total number of FNAs. This value was only calculated for studies providing data for all six categories. Resection rate (RR) was the proportion of surgically resected cases among the total number of FNAs in that category. The risk of malignancy (ROM) was considered the proportion of malignant cases confirmed by histopathological examination among the resected cases. For studies containing potentially overlapping data from the same institution, we selected studies with the largest number of FNAs.

We used the statistical software Comprehensive Metaanalysis (Englewood, New Jersey) and JAMOVI (https:// www.jamovi.org), which is built in the $\mathrm{R}$ statistical language, for statistical analyses. A meta-analysis of proportion and its $95 \%$ confidence intervals (CIs) were pooled using the random-effect model.

The heterogeneity among the included studies was based on the $\mathrm{I}^{2}$ statistic (6). The degree of heterogeneity was categorized as low, moderate, and high with a value of $25 \%$ to $49 \%, 50 \%$ to $74 \%$, and $\geq 75 \%$, respectively (7). The origins of heterogeneity were further examined using metaregression and subgroup analysis. For subgroup analysis, if the two range values of $95 \%$ CI do not overlap with each other, it signifies a statistical result. Otherwise, no statistical difference between the two subgroups is present. 


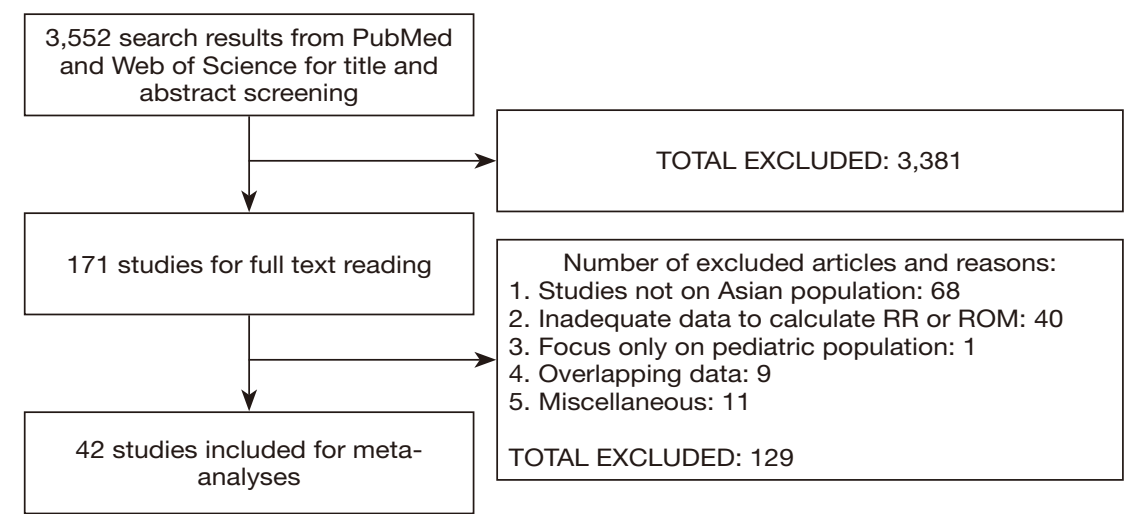

Figure 1 Study flowchart.

\section{Risk of bias and publication bias assessment}

We rated the methodological quality of the included studies according to the National Heart, Lung, and Blood Institute (NHLBI) assessment tool (8). To assess the publication bias, we used the Egger's regression test and funnel plot of estimates (9). A P value $<0.05$ was considered statistically significant publication bias.

\section{Results}

A total of 3,552 articles was found for the title and abstract screening and 171 of them were included for the fulltext reading. We further excluded 129 studies and finally included 42 Asian studies with 84,953 thyroid nodules for meta-analysis (Figure 1). The baseline characteristics of all included studies are presented in Table 1 .

The majority of studies were retrospective studies. TBSRTC 2009 was used to classify thyroid nodules in all studies. The Asian regions included in this study were Eastern [China (10-13), Japan (25), and Korea (26-42)], South Central [India (14-22), Israel $(23,24)$. Nepal (43)], Middle East [Saudi Arabia (44-47)], and Southeast Asia [Singapore $(48,49)$, Thailand $(50,51)]$.

Using the NHLBI assessment tool, the majority of included studies were fair to good quality (Table S1).

\section{Overall frequency, RR, and ROM of each TBSRTC category among Asian countries}

Pooled frequencies, RRs, and ROMs of the six TBSRTC categories were shown in Table 2. Among six categories, benign was most commonly diagnosed accounting for nearly $60 \%$ of FNAs, followed by malignant and ND categories.
Regarding meta-analyses for frequency, a low and moderate heterogeneity was present in some of the meta-analyses.

The RR was highest in malignant and SM categories and lowest in benign nodules. Among the meta-analyses for $\mathrm{RR}$, a low heterogeneity $\left(25 \leq \mathrm{I}^{2}<50 \%\right)$ was seen in analyses for the ND category. Additionally, a moderate amount of heterogeneity $\left(50 \% \leq \mathrm{I}^{2}<75 \%\right)$ was present in SM and malignant categories.

Similar to RR, ROM was highest in malignant and $\mathrm{SM}$ and lowest in the benign subgroup. No significant heterogeneity was present in meta-analyses for ROM $\left(\mathrm{I}^{2}\right.$ $<25 \%$ ), except the AUS/FLUS category.

\section{Subgroup analyses and meta-regression to explore the sources of heterogeneity}

We ran the meta-regression to search for heterogeneity origins. Meta-regression results showed that the difference in study origin and the use of molecular testing mostly influence the heterogeneity degrees in TBSRTC outputs (Figure 2). Other confounding factors such as year of publication, study design, and the use of ultrasound-guided FNA less likely affected the deviations among the log event rate and regression line (data not shown).

We divided studies into two subgroups of using and not using molecular testing (Table 3). Among studies using molecular testing, no studies used multigene panel testing (e.g., Afirma gene expression classifier, ThyroSeq) and all used single-gene testing (e.g., pyrosequencing, Sanger sequencing). Following subgroup analyses, there were some significant differences in RR and ROM between studying employing and not employing molecular testing. The ROM significantly increased in the benign, AUS/FLUS, FN/SFN, 
Table 1 Baseline characteristics of 42 included studies

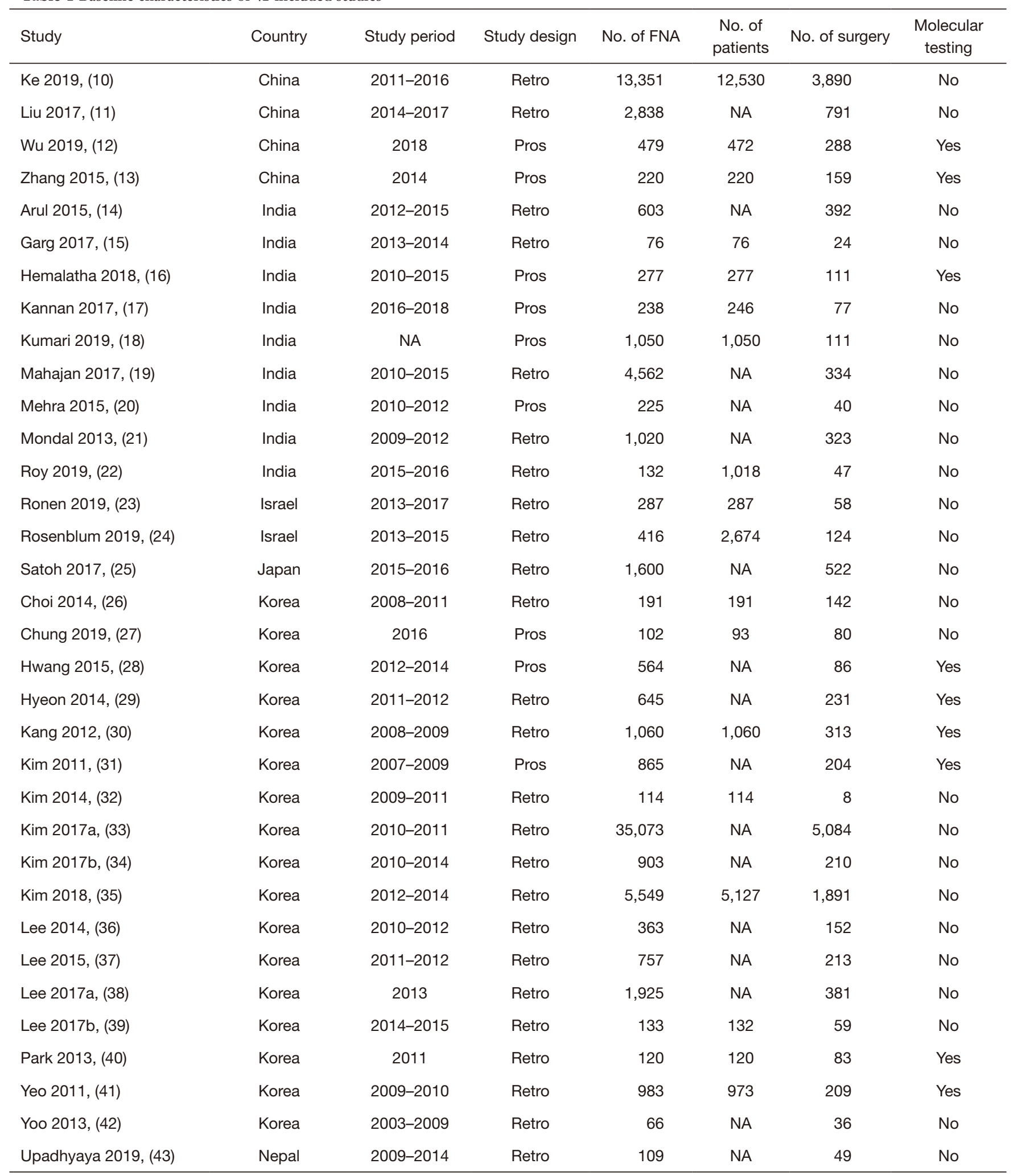

Table 1 (continued) 
Table 1 (continued)

\begin{tabular}{|c|c|c|c|c|c|c|c|}
\hline Study & Country & Study period & Study design & No. of FNA & $\begin{array}{c}\text { No. of } \\
\text { patients }\end{array}$ & No. of surgery & $\begin{array}{c}\text { Molecular } \\
\text { testing }\end{array}$ \\
\hline Al Dawish 2017, (44) & Saudi Arabia & 2012-2014 & Retro & 1,433 & 1,188 & 369 & No \\
\hline Al-Abbadi 2013, (45) & Saudi Arabia & 2010-2011 & Retro & 205 & 186 & 64 & No \\
\hline Alabdulqader 2015, (46) & Saudi Arabia & 2012-2013 & Retro & 252 & 218 & 45 & No \\
\hline Lim 2018, (49) & Singapore & 2008-2015 & Retro & 111 & 88 & 88 & No \\
\hline Limlunjakorn 2017, (50) & Thailand & 2010-2015 & Retro & 2,762 & NA & 457 & No \\
\hline Thewjitcharoen 2019, (51) & Thailand & 2010-2017 & Retro & 2,735 & 2,115 & 188 & No \\
\hline
\end{tabular}

FNA, fine-needle aspiration; retro, retrospective; pros, prospective; NA, not available.

Table 2 Summary of frequency, resection rate, and malignancy risk of thyroid cytology practice among Asian countries using TBSRTC

\begin{tabular}{|c|c|c|c|c|c|c|c|c|c|}
\hline \multirow{2}{*}{ Category } & \multicolumn{3}{|c|}{ Frequency (\%) } & \multicolumn{3}{|c|}{ Resection rate (\%) } & \multicolumn{3}{|c|}{ Risk of malignancy (\%) } \\
\hline & $\%$ & $95 \% \mathrm{Cl}$ & $1^{2}$ & $\%$ & $95 \% \mathrm{Cl}$ & $\mathrm{I}^{2}$ & $\%$ & $95 \% \mathrm{Cl}$ & $\mathrm{I}^{2}$ \\
\hline Nondiagnostic & 8.0 & $6.0-10.6$ & $51.3^{*}$ & 13.5 & $9.6-18.7$ & $26.9^{\star}$ & 37.1 & $27.8-47.4$ & 8.6 \\
\hline Benign & 59.7 & $52.7-66.3$ & $26.1^{*}$ & 9.3 & $5.8-14.5$ & 4.6 & 13.9 & $10.0-19.0$ & 17.2 \\
\hline AUS/FLUS & 7.3 & $6.1-8.8$ & $74.7^{\star}$ & 31.1 & $26.2-36.4$ & 20.4 & 54.3 & $46.4-61.9$ & $26.6^{*}$ \\
\hline SM & 4.4 & $3.4-5.7$ & $47.1^{*}$ & 68.1 & $62.4-73.3$ & $53.6^{*}$ & 89.3 & $83.8-93.1$ & 5.1 \\
\hline Malignant & 9.7 & $7.2-12.8$ & 22 & 74.0 & $68.0-79.2$ & $59.5^{\star}$ & 98.1 & $96.5-99.0$ & 0 \\
\hline
\end{tabular}

*, indicates a significant amount of heterogeneity among the included studies (>25\%). AUS/FLUS, atypia of undetermined significance/ follicular lesion of undetermined significance; FN/SFN, follicular neoplasm/suspicious for a follicular neoplasm; SM, suspicious of malignancy; $\mathrm{Cl}$, confidence interval.

and SM categories following the application of molecular testing (Table 3).

\section{Publication bias}

To examine the presence of publication bias, funnel plots of effects pooled from individual studies were evaluated. Funnel plots showed no strong evidence of publication bias among the set of included studies and Egger's regression test confirmed the absence of publication bias (Figure S1).

\section{Discussion}

Asia is the largest continent which has the highest population in the world and includes many geographic regions with varied cultures and religions. Most Asian countries have a modern health care system and update contemporary medical knowledge. Since TBSRTC was introduced in 2009, it has been widely accepted in Asian cytology practice $(2,3)$. Besides that, Asia has a high prevalence of thyroid cancer (52). The GLOBOCAN database estimated that $45.8 \%$ of all new thyroid cancer cases in 2018 were diagnosed in Asia (52). Most of the published meta-analyses on thyroid FNA did not include Asian publications (53-56). Our study provided a general insight and experience regarding thyroid cytopathology practices among Asian countries. Hopefully, our metaanalysis result can contribute to the future revision of TBSRTC.

In our meta-analysis, the patients with indeterminate 

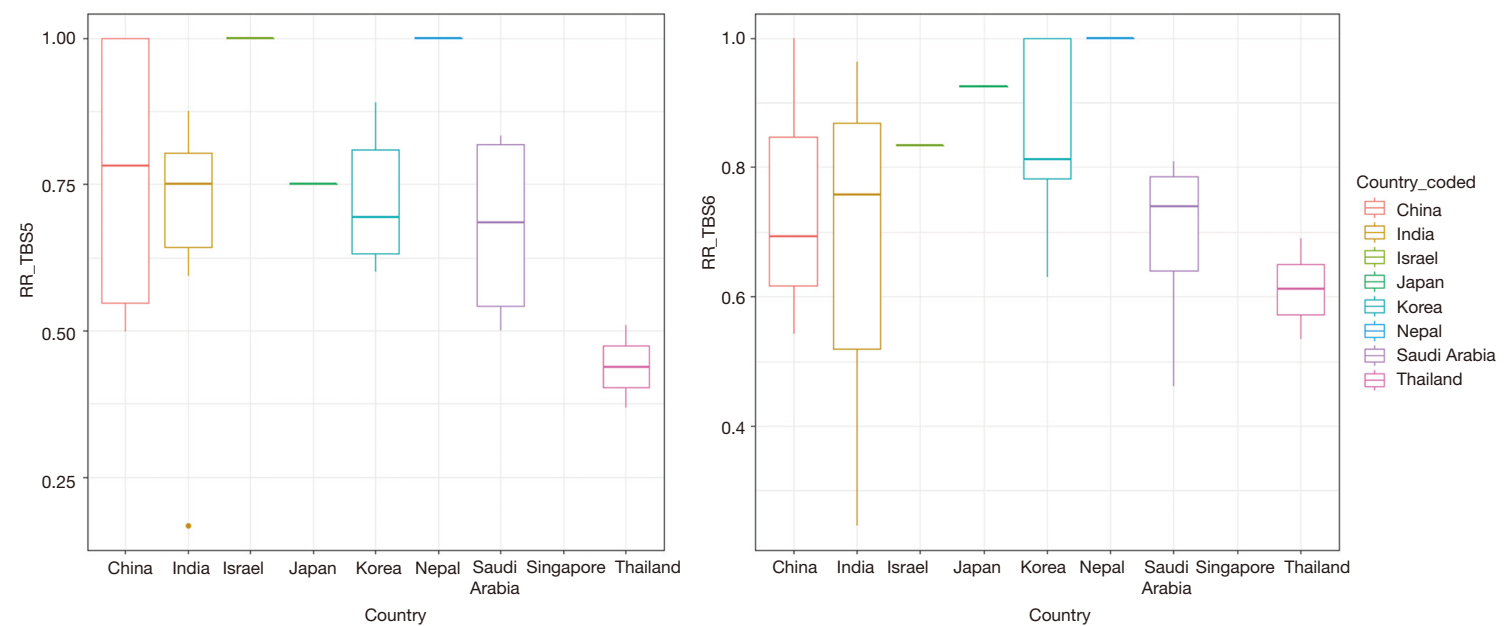

Figure 2 Boxplots illustrating the resection rate of TBSRTC categories V (left) and VI (right) among Asian countries show a higher resection rate among Eastern Asian countries (China, Korea, Japan), South-central Asia (India, Nepal, Israel), and Middle East (Saudi Arabia), and a lower resection rate among Southeast Asian countries (Thailand).

thyroid nodules (AUS/FLUS and FN/SFN) account for about $10 \%$ of preoperative FNAs. Compared to results from Western countries, this rate was lower $(4,55)$. The reason for this difference might be because the prevalence of follicular variant papillary thyroid carcinoma (PTC) has been increasing over the years in Western countries (57), and the rate of follicular variant PTC in Asia tends to be much lower in comparison with the classical variant (58). Many encapsulated follicular variant PTC are preoperatively diagnosed as FN/SFN. The RR of AUS/FLUS and FN/SFN nodules among Asian countries were lower as compared to Western practice $(31.1 \%$ versus $40.5 \%$, and $56.1 \%$ versus $63.4 \%$, respectively) (4). Conversely, the ROM of AUS/FLUS and FN/SFN among Asian institutions were higher than the implied ROM of Western countries $(54.3 \%$ versus $21.5 \%$ and $33.3 \%$ versus 27.3 , respectively) (4). A low $\mathrm{RR}$ and high ROM of indeterminate categories is a distinctive feature of Asian cytology practice as compared with Western countries (4). The underlying reason for this difference is the active surveillance strategy to those with benign clinical findings until they are determined any suspicious features. Japan has established the Japan Thyroid Association (JTA) guidelines for the treatment of thyroid nodules (59). According to the JTA guidelines, patients with FN/SFN nodules having benign clinical information are not indicated for surgery and they should be routinely followed-up $(59,60)$. Thus, diagnostic surgery is only indicated for patients with suspicious clinical and sonographic findings. This management approach can help reduce the overtreatment of borderline/precursor thyroid tumors and low-risk thyroid carcinomas (60). Korean clinicians flexibly and selectively adopted the ATA 2015 guideline and recommended active surveillance for patients with $\mathrm{PTC}<1 \mathrm{~cm}$ in diameter as well as molecular testing for the indeterminate nodules $(31,61)$. The most characteristic features of Korea thyroid cytology practice are the applications of core-needle biopsy and molecular testing which are not commonly used in other Asian countries $(31,62)$. Additionally, Asian cytopathologists have stricter diagnostic criteria for PTC type nuclear features. The majority of cases with incomplete PTC type nuclear features were categorized in AUS/FLUS in most Asian practice, but Western cytopathologists often classified in the SM category. Hirokawa et al. observed that the frequency of diagnosis of encapsulated follicular variant PTC among American pathologists (25\%) was remarkably higher than that (4\%) among Japanese pathologists (63). A recently inter- and intra-observer variation study by Liu et al. regarding the diagnosis of noninvasive follicular thyroid neoplasm with papillary-like nuclear features (NIFTP) among nine Asian cytopathologists showed a moderate agreement (kappa value $=0.452$ ), which is different from a report by Thompson et al. (kappa value $=0.66)(64,65)$. Several factors can lead to these discrepancies including working and geographic differences, individual interpretation of diagnostic criteria, and investigation method (virtual slide versus still image). 


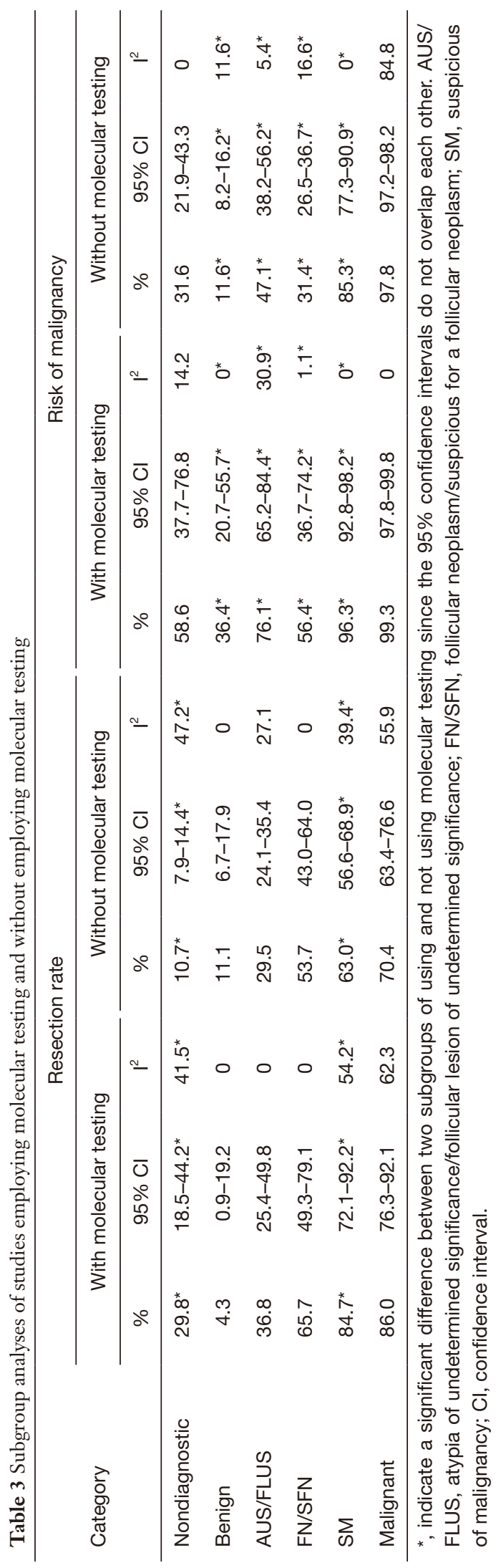

Interestingly, the pooled ROM for the benign category in this study was $13.9 \%$ which is higher than the implied ROM (0-3\%) by the Bethesda system (2,3). A close follow-up of patients with benign cytological nodule is recommended in most Asian countries to minimize false negative diagnosis to confirm they are truly benign. During follow-up of benign nodules, malignant cases are inevitably identified in later years, as false negative cases in a certain proportion, which increases ROM in this category. Another potential reason is that aspirates with "cystic fluid only" are usually included in this category by Asian cytopathologists $(11,59,60,66,67)$, instead of in the ND category as recommended by TBSRTC $(2,3)$. It may result in the presence of cystic PTCs and a higher ROM.

Our meta-analysis also showed that there is a significant amount of heterogeneity among the Asian cytology practice. The amount of heterogeneity was low to moderate (Table 2). These heterogeneities might origin from diverse clinical approaches and diagnostic concepts among the institutions, different prevalence of thyroid cancer among countries, or individual pathologists. Our meta-regression results showed that the difference in study origin and the use of molecular testing are the two major factors causing these heterogeneities (Figure 2 and Table 3). Regarding RR, a low heterogeneity was present for ROM in the AUS/ FLUS category. A low RR and high ROM were seen in Korea because clinicians recommended active surveillance for patients with PTC $<1 \mathrm{~cm}$ in diameter and applied molecular testing $(31,61)$. Other countries such as India and Southeast Asian countries usually follow the ATA or TBSRTC guidelines resulted in a lower ROM $(4,60)$. On the other side, a moderate amount of heterogeneity was present in SM and malignant categories; while no significant heterogeneity was seen among indeterminate categories. An explanation for this finding is the low rates of patients undergoing surgery in Southeast Asian countries (Figure 2). In these countries, patients are transferred to institutions in large cities due to the lack of formal cytopathology department and educational courses in rural areas $(66,68,69)$. After FNA and thyroid workup, many patients returned to their hometown for the thyroid operation. Unfortunately, their surgical and histopathological reports were not available to access due to the lack of connections between hospitals resulting in missing surgical data and a lower RR in these countries.

Recently, preoperative molecular testing has been recommended in international guidelines $(3,70)$, especially for indeterminate thyroid nodules to decrease the rate 
of overdiagnosis and overtreatment, and to reduce the potential complication of diagnostic surgery. Our study results indicated that ROM significantly increases in the benign, AUS/FLUS, FN/SFN, and SM categories after the application of molecular testing. Therefore, preoperative molecular testing has an important role to accurately select the patients for surgery. However, these methods are not readily available in many Asian countries, especially in developing countries due to the expensive cost. In the USA, the patients have to pay $\$ 300$ if they have an insurance provider and $\$ 3,200$ to $\$ 4,875$ without insurance coverage to undergo molecular testing (71). In contrast, most Asian clinicians apply active surveillance for indeterminate nodules which has a lower cost.

In 2016, the NIFTP reclassification was introduced to reduce the risk of overdiagnosis and overtreatment of encapsulated follicular variant PTC. TBSRTC 2017 adopted the NIFTP terminology and provided two ranges of ROM, one considering NIFTP malignancy and another not (3). In the present study, all included studies used the TBSRTC 2009 so it would not affect the overall analysis. The changes in ROM following the NIFTP reclassification were summarized in a recent meta-analysis which showed a reduced ROM in all categories, particularly the indeterminate nodules (72). The impact of NIFTP reclassification on ROM was more significant in Western than in Asian practice (72).

There are some limitations in this study that need to be addressed. These are unavoidable selection bias because the majority of our data were retrospective. Besides, a considerable amount of heterogeneity is still present following subgroup analyses. Another limitation is that incidentalomas data were not provided in most of the included studies and it might affect the true ROM. Finally, difference in the number of studies between countries is a potential factor that can affect the analysis. Data from Korea were predominant in our study while data from Japan, the Middle East, and Southeast Asian countries were not commonly reported.

\section{Conclusions}

In conclusion, our meta-analysis provided insight regarding thyroid cytology practice among Asian countries. Active surveillance to reduce unnecessary diagnostic surgery is common in Asian practice resulting in a low RR and high ROM for indeterminate nodules. We also highlighted the usefulness of preoperative molecular testing to classify the patient accurately for surgery. There were still variations in general thyroid cytology practice which might originate from different practice guidelines among Asian countries. Future guidelines and consensus regarding the application of TBSRTC in thyroid cytology practice among Asian countries are required to reduce these heterogeneities.

\section{Acknowledgments}

Funding: None.

\section{Footnote}

Provenance and Peer Review: This article was commissioned by the Guest Editor (Kennichi Kakudo) for the series "Asian and Western Practice in Thyroid Pathology: Similarities and Differences" published in Gland Surgery. The article was sent for external peer review organized by the Guest Editor and the editorial office.

Reporting Checklist: The authors have completed the PRISMA reporting checklist. Available at http://dx. doi. org/10. 21037/gs-20-404

Peer Review File: Available at http://dx. doi. org/10.21037/ gs-20-404

Conflicts of Interest: All authors have completed the ICMJE uniform disclosure form (available at http://dx. doi. org/10. 21037/gs-20-404). The series "Asian and Western Practice in Thyroid Pathology: Similarities and Differences" was commissioned by the editorial office without any funding or sponsorship. KK served as the unpaid Guest Editor of the series and serves as an unpaid editorial board member of Gland Surgery from Sep 2018 to Aug 2020. The authors have no other conflicts of interest to declare.

Ethical Statement: The authors are accountable for all aspects of the work in ensuring that questions related to the accuracy or integrity of any part of the work are appropriately investigated and resolved.

Open Access Statement: This is an Open Access article distributed in accordance with the Creative Commons Attribution-NonCommercial-NoDerivs 4.0 International License (CC BY-NC-ND 4.0), which permits the noncommercial replication and distribution of the article with the strict proviso that no changes or edits are made and the 
original work is properly cited (including links to both the formal publication through the relevant DOI and the license). See: https://creativecommons.org/licenses/by-nc-nd/4.0/.

\section{References}

1. Al-Abbadi MA, Shareef SQ, Yousef MM, et al. A follow-up study on thyroid aspirates reported as atypia of undetermined significance/follicular lesion of undetermined significance and follicular neoplasm/ suspicious for follicular neoplasm: A multicenter study from the Arabian Gulf region. Diagn Cytopathol 2017;45:983-8.

2. Cibas ES, Ali SZ. The Bethesda System for Reporting Thyroid Cytopathology. Thyroid 2009;19:1159-65.

3. Cibas ES, Ali SZ. The 2017 Bethesda System for Reporting Thyroid Cytopathology. Thyroid 2017;27:1341-6.

4. Vuong HG, Ngo HTT, Bychkov A, et al. Differences in surgical resection rate and risk of malignancy in thyroid cytopathology practice between Western and Asian countries: A systematic review and meta-analysis. Cancer Cytopathol 2020;128:238-49.

5. Moher D, Liberati A, Tetzlaff J, et al. Preferred reporting items for systematic reviews and meta-analyses: the PRISMA statement. PLoS Med 2009;6:e1000097.

6. Higgins JP, Thompson SG. Quantifying heterogeneity in a meta-analysis. Stat Med 2002;21:1539-58.

7. Ioannidis JP, Patsopoulos NA, Evangelou E. Uncertainty in heterogeneity estimates in meta-analyses. BMJ 2007;335:914-6.

8. National Heart L, and Blood Institute. Quality assessment tool for observational cohort and cross-sectional studies. 2014.

9. Egger M, Davey Smith G, Schneider M, et al. Bias in meta-analysis detected by a simple, graphical test. BMJ 1997;315:629-34.

10. Ke J, Jianyong L, Ying L, et al. The use of The Bethesda System for Reporting Thyroid Cytopathology in a Chinese population: An analysis of 13351 specimens. Diagn Cytopathol 2019;47:876-80.

11. Liu Z, Liu D, Ma B, et al. History and Practice of Thyroid Fine-Needle Aspiration in China, Based on Retrospective Study of the Practice in Shandong University Qilu Hospital. J Pathol Transl Med 2017;51:528-32.

12. $\mathrm{Wu} \mathrm{Y,} \mathrm{Xu} \mathrm{T,} \mathrm{Cao} \mathrm{X,} \mathrm{et} \mathrm{al.} \mathrm{BRAF} \mathrm{(V600E)} \mathrm{vs.} \mathrm{TIRADS} \mathrm{in}$ predicting papillary thyroid cancers in Bethesda system I, III, and V nodules. Cancer Biol Med 2019;16:131-8.

13. Zhang YZ, Xu T, Cui D, et al. Value of TIRADS,
BSRTC and FNA-BRAF V600E mutation analysis in differentiating high-risk thyroid nodules. Sci Rep 2015;5:16927.

14. Arul P, Akshatha C, Masilamani S. A study of malignancy rates in different diagnostic categories of the Bethesda system for reporting thyroid cytopathology: An institutional experience. Biomed J 2015;38:517-22.

15. Garg S, Naik LP, Kothari KS, et al. Evaluation of thyroid nodules classified as Bethesda category III on FNAC. J Cytol 2017;34:5-9.

16. Hemalatha R, Pai R, Manipadam MT, et al. Presurgical Screening of Fine Needle Aspirates from Thyroid Nodules for BRAF Mutations: A Prospective Single Center Experience. Indian J Endocrinol Metab 2018;22:785-92.

17. Kannan S, Raju N, Kekatpure V, et al. Improving Bethesda Reporting in Thyroid Cytology: A Team Effort Goes a Long Way and Still Miles to Go. Indian J Endocrinol Metab 2017;21:277-81.

18. Kumari KA, Jadhav PD, Prasad C, et al. Diagnostic Efficacy of Ultrasound-Guided Fine Needle Aspiration Combined with the Bethesda System of Reporting. J Cytol 2019;36:101-5.

19. Mahajan S, Srinivasan R, Rajwanshi A, et al. Risk of Malignancy and Risk of Neoplasia in the Bethesda Indeterminate Categories: Study on 4,532 Thyroid FineNeedle Aspirations from a Single Institution in India. Acta Cytol 2017;61:103-10.

20. Mehra P, Verma AK. Thyroid cytopathology reporting by the bethesda system: a two-year prospective study in an academic institution. Patholog Res Int 2015;2015:240505.

21. Mondal SK, Sinha S, Basak B, et al. The Bethesda system for reporting thyroid fine needle aspirates: A cytologic study with histologic follow-up. Journal of Cytology 2013;30:94-9.

22. Roy S, Prabhu AJ, Abraham DT, et al. An Insight into the Utility of Sub-Categorisation of Atypia of Undetermined Significance for Risk Stratification: A Retrospective Study on an Indian Cohort with Histopathological Correlation. Acta Cytol 2019;63:182-8.

23. Ronen $\mathrm{O}$, Cohen $\mathrm{H}, \mathrm{Abu} M$. Review of a single institution's fine needle aspiration results for thyroid nodules: Initial observations and lessons for the future. Cytopathology 2019;30:468-74.

24. Rosenblum RC, Shtabsky A, Marmor S, et al. Indeterminate nodules by the Bethesda system for reporting thyroid cytopathology in Israel: Frequency, and risk of malignancy after reclassification of follicular thyroid neoplasm with papillary-like features. Eur J Surg Oncol 
2019;45:1182-7.

25. Satoh S, Yamashita H, Kakudo K. Thyroid Cytology: The Japanese System and Experience at Yamashita Thyroid Hospital. J Pathol Transl Med 2017;51:548-54.

26. Choi YJ, Baek JH, Ha EJ, et al. Differences in Risk of Malignancy and Management Recommendations in Subcategories of Thyroid Nodules with Atypia of Undetermined Significance or Follicular Lesion of Undetermined Significance: The Role of UltrasoundGuided Core-Needle Biopsy. Thyroid 2014;24:494-501.

27. Chung SR, Baek JH, Choi YJ, et al. The Role of Core Needle Biopsy for the Evaluation of Thyroid Nodules with Suspicious Ultrasound Features. Korean J Radiol 2019;20:158-65.

28. Hwang TS, Kim WY, Han HS, et al. Preoperative RAS Mutational Analysis Is of Great Value in Predicting Follicular Variant of Papillary Thyroid Carcinoma. Biomed Res Int 2015;2015:697068.

29. Hyeon J, Ahn S, Shin JH, et al. The prediction of malignant risk in the category "atypia of undetermined significance/follicular lesion of undetermined significance" of the Bethesda System for Reporting Thyroid Cytopathology using subcategorization and BRAF mutation results. Cancer Cytopathol 2014;122:368-76.

30. Kang G, Cho EY, Shin JH, et al. Role of BRAFV600E mutation analysis and second cytologic review of fineneedle aspiration for evaluating thyroid nodule. Cancer Cytopathol 2012;120:44-51.

31. Kim SK, Hwang TS, Yoo YB, et al. Surgical results of thyroid nodules according to a management guideline based on the BRAF(V600E) mutation status. J Clin Endocrinol Metab 2011;96:658-64.

32. Kim GR, Yoon JH, Kim EK, et al. Benign Aspirates on Follow-Up FNA May Be Enough in Patients with Initial Atypia of Undetermined Significance/Follicular Lesion of Undetermined Significance. Int J Endocrinol 2014;2014:354612.

33. Kim M, Park HJ, Min HS, et al. The Use of the Bethesda System for Reporting Thyroid Cytopathology in Korea: A Nationwide Multicenter Survey by the Korean Society of Endocrine Pathologists. J Pathol Transl Med 2017;51:410-7.

34. Kim SD, Han SH, Jeong WJ, et al. Differences in Clinical Features Between Subcategories of "Atypia/Follicular Lesion of Undetermined Significance". Endocr Pathol 2017;28:247-52.

35. Kim M, Kim JE, Kim HJ, et al. Cytologic Diagnosis of Noninvasive Follicular Thyroid Neoplasm with Papillary- like Nuclear Features and Its Impact on the Risk of Malignancy in the Bethesda System for Reporting Thyroid Cytopathology: An Institutional Experience. J Pathol Transl Med 2018;52:171-8.

36. Lee KH, Shin JH, Oh YL, et al. Atypia of Undetermined Significance in Thyroid Fine-Needle Aspiration Cytology: Prediction of Malignancy by US and Comparison of Methods for Further Management. Ann Surg Oncol 2014;21:2326-31.

37. Lee YS, Kim HK, Chang H, et al. Diagnostic Thyroidectomy May Be Preferable in Patients With Suspicious Ultrasonography Features After Cytopathology Diagnosis of AUS/FLUS in the Bethesda System. Medicine (Baltimore) 2015;94:e2183.

38. Lee YB, Cho YY, Jang JY, et al. Current status and diagnostic values of the Bethesda system for reporting thyroid cytopathology in a papillary thyroid carcinomaprevalent area. Head Neck 2017;39:269-74.

39. Lee JH, Han K, Kim EK, et al. Risk Stratification of Thyroid Nodules With Atypia of Undetermined Significance/Follicular Lesion of Undetermined Significance (AUS/FLUS) Cytology Using Ultrasonography Patterns Defined by the 2015 ATA Guidelines. Ann Otol Rhinol Laryngol 2017;126:625-33.

40. Park SJ, Sun JYH, Hong K, et al. Application of BRAF, NRAS, KRAS mutations as markers for the detection of papillary thyroid cancer from FNAB specimens by pyrosequencing analysis. Clin Chem Lab Med 2013;51:1673-80.

41. Yeo MK, Liang ZL, Oh T, et al. Pyrosequencing cut-off value identifying BRAF(V600E) mutation in fine needle aspiration samples of thyroid nodules. Clin Endocrinol (Oxf) 2011;75:555-60.

42. Yoo C, Choi HJ, Im S, et al. Fine Needle Aspiration Cytology of Thyroid Follicular Neoplasm: Cytohistologic Correlation and Accuracy. Korean J Pathol 2013;47:61-6.

43. Upadhyaya P, Dhakal S, Adhikari P, et al. Histopathological Review of Diagnostic Categories of the Bethesda System for Reporting Thyroid Cytopathology - An Institutional Experience of 5 Years. J Cytol 2019;36:48-52.

44. Al Dawish MA, Robert AA, Muna A, et al. Bethesda System for Reporting Thyroid Cytopathology: A threeyear study at a tertiary care referral center in Saudi Arabia. World J Clin Oncol 2017;8:151-7.

45. Al-Abbadi MA, Shareef SQ, Ali JA, et al. Application of the Bethesda System for Reporting Thyroid Cytopathology in the Eastern Province of Saudi Arabia: Phase I Pilot Retrospective Analysis. Acta Cytologica 2013;57:481-8. 
46. Alabdulqader NA, Shareef SQ, Ali JA, et al. Application of the Bethesda System for Reporting Thyroid Cytopathology in the Eastern Province of Saudi Arabia: A Follow-Up Study. Acta Cytol 2015;59:233-8.

47. Mufti ST, Molah R. The bethesda system for reporting thyroid cytopathology: a five-year retrospective review of one center experience. Int J Health Sci (Qassim) 2012;6:159-73.

48. Gan TR, Nga ME, Lum JH, et al. Thyroid cytologynuclear versus architectural atypia within the "Atypia of undetermined significance/follicular lesion of undetermined significance" Bethesda category have significantly different rates of malignancy. Cancer Cytopathol 2017;125:245-56.

49. Lim JXY, Nga ME, Chan DKH, et al. Subclassification of Bethesda Atypical and Follicular Neoplasm Categories According to Nuclear and Architectural Atypia Improves Discrimination of Thyroid Malignancy Risk. Thyroid 2018;28:511-21.

50. Limlunjakorn P, Keelawat S, Bychkov A. Evaluation of Thyroid Fine Needle Aspiration Cytology by the Bethesda Reporting System: A Retrospective Analysis of Rates and Outcomes from the King Chulalongkorn Memorial Hospital. J Med Assoc Thai 2017;100:783.

51. Thewjitcharoen Y, Butadej S, Nakasatien S, et al. Incidence and malignancy rates classified by The Bethesda System for Reporting Thyroid Cytopathology (TBSRTC) - An 8-year tertiary center experience in Thailand. J Clin Transl Endocrinol 2019;16:100175.

52. Bray F, Ferlay J, Soerjomataram I, et al. Global cancer statistics 2018: GLOBOCAN estimates of incidence and mortality worldwide for 36 cancers in 185 countries. CA Cancer J Clin 2018;68:394-424.

53. Sheffield BS, Masoudi H, Walker B, et al. Preoperative diagnosis of thyroid nodules using the Bethesda System for Reporting Thyroid Cytopathology: a comprehensive review and meta-analysis. Expert Rev Endocrinol Metab 2014;9:97-110.

54. Krauss EA, Mahon M, Fede JM, et al. Application of the Bethesda Classification for Thyroid Fine-Needle Aspiration: Institutional Experience and Meta-analysis. Arch Pathol Lab Med 2016;140:1121-31.

55. Bongiovanni M, Spitale A, Faquin WC, et al. The Bethesda System for Reporting Thyroid Cytopathology: a meta-analysis. Acta Cytol 2012;56:333-9.

56. Bychkov A, Kakudo K, Hong S. Current Practices of Thyroid Fine-Needle Aspiration in Asia: A Missing Voice. J Pathol Transl Med 2017;51:517-20.
57. Romei C, Fugazzola L, Puxeddu E, et al. Modifications in the papillary thyroid cancer gene profile over the last 15 years. J Clin Endocrinol Metab 2012;97:E1758-65.

58. Vuong HG, Altibi AM, Abdelhamid AH, et al. The changing characteristics and molecular profiles of papillary thyroid carcinoma over time: a systematic review. Oncotarget 2017;8:10637-49.

59. Kakudo K, Kameyama K, Miyauchi A, et al. Introducing the reporting system for thyroid fine-needle aspiration cytology according to the new guidelines of the Japan Thyroid Association. Endocr J 2014;61:539-52.

60. Kakudo K, Higuchi M, Hirokawa M, et al. Thyroid FNA cytology in Asian practice-Active surveillance for indeterminate thyroid nodules reduces overtreatment of thyroid carcinomas. Cytopathology 2017;28:455-66.

61. Yi KH. The Revised 2016 Korean Thyroid Association Guidelines for Thyroid Nodules and Cancers: Differences from the 2015 American Thyroid Association Guidelines. Endocrinol Metab (Seoul) 2016;31:373-8.

62. Lee S, Park G, Jung S, et al. Core-needle biopsy for the preoperative diagnosis of follicular neoplasm in thyroid nodule screening: A validation study. Pathology - Research and Practice 2015;212.

63. Hirokawa M, Carney JA, Goellner JR, et al. Observer variation of encapsulated follicular lesions of the thyroid gland. Am J Surg Pathol 2002;26:1508-14.

64. Liu Z, Bychkov A, Jung CK, et al. Interobserver and intraobserver variation in the morphological evaluation of noninvasive follicular thyroid neoplasm with papillary-like nuclear features in Asian practice. Pathol Int 2019;69:202-10.

65. Thompson LDR, Poller DN, Kakudo K, et al. An International Interobserver Variability Reporting of the Nuclear Scoring Criteria to Diagnose Noninvasive Follicular Thyroid Neoplasm with Papillary-Like Nuclear Features: a Validation Study. Endocr Pathol 2018;29:242-9.

66. Keelawat S, Rangdaeng S, Koonmee S, et al. Current Status of Thyroid Fine-Needle Aspiration Practice in Thailand. J Pathol Transl Med 2017;51:565-70.

67. Takada N, Hirokawa M, Suzuki A, et al. Reappraisal of "cyst fluid only" on thyroid fine-needle aspiration cytology. Endocr J 2017;64:759-65.

68. Abelardo AD. Thyroid Fine-Needle Aspiration Practice in the Philippines. J Pathol Transl Med 2017;51:555-9.

69. Nguyen HL, Nghia N, Lewis H. Quality Practices of Anatomic Pathology Labs in Vietnam. Critical Values 2016;9:22-5. 
70. Haugen BR, Alexander EK, Bible KC, et al. 2015 American Thyroid Association Management Guidelines for Adult Patients with Thyroid Nodules and Differentiated Thyroid Cancer: The American Thyroid Association Guidelines Task Force on Thyroid Nodules and Differentiated Thyroid Cancer. Thyroid 2016;26:1-133.

71. Li H, Robinson K, Anton B, et al. Cost-Effectiveness of a Novel Molecular Test for Cytologically Indeterminate

Cite this article as: Nguyen TPX, Truong VT, Kakudo K, Vuong HG. The diversities in thyroid cytopathology practices among Asian countries using the Bethesda system for reporting thyroid cytopathology. Gland Surg 2020;9(5):1735-1746. doi: $10.21037 / g s-20-404$
Thyroid Nodules. J Clin Endocrinol Metab 2011;96:E1719-26.

72. Vuong HG, Tran TTK, Bychkov A, et al. Clinical impact of non-invasive follicular thyroid neoplasm with papillarylike nuclear features on the risk of malignancy in the Bethesda system for reporting thyroid cytopathology: a meta-analysis of 14,153 resected thyroid nodules. Endocr Pract 2019;25:491-502. 


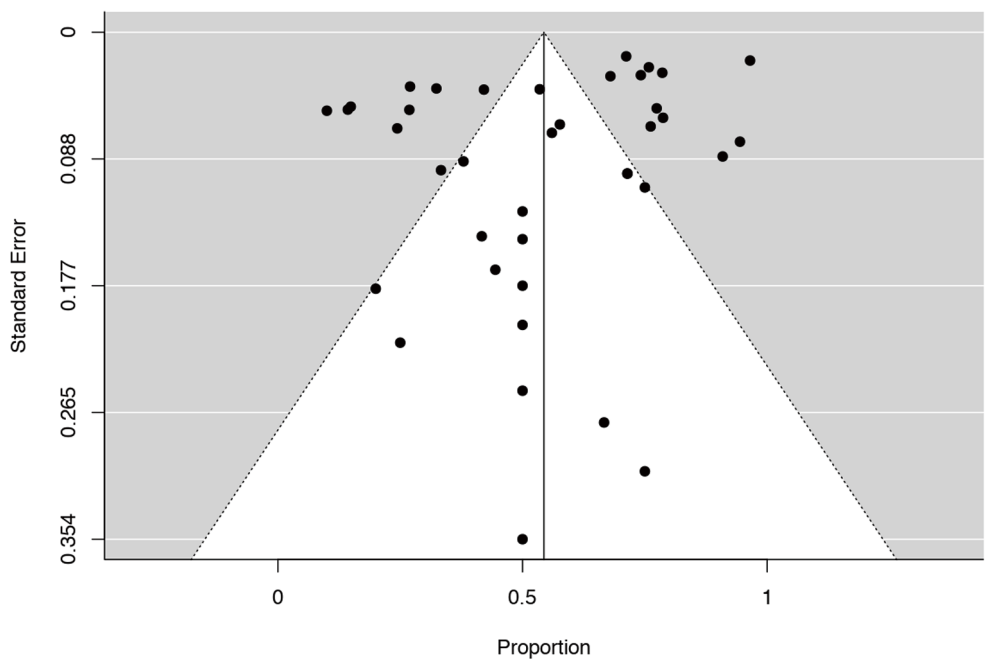

Figure S1 Funnel plot showed no strong evidence of publication among the set of studies regarding the resection rate in AUS/FLUS category. Egger's regression test confirmed the absence of publication bias ( $\mathrm{P}=0.491)$. AUS/FLUS, atypia of undetermined significance/ follicular lesion of undetermined significance. 
Table S1 Quality assessment of included studies

\begin{tabular}{|c|c|c|c|c|c|c|c|c|c|c|c|c|c|c|c|}
\hline Study & Q1 & Q2 & Q3 & Q4 & Q5 & Q6 & Q7 & Q8 & Q9 & Q10 & Q11 & Q12 & Q13 & Q14 & $\begin{array}{c}\text { Quality } \\
\text { rating }\end{array}$ \\
\hline Bak 2015 & Yes & Yes & NR & Yes & Yes & Yes & Yes & Yes & Yes & No & Yes & NR & Yes & Yes & Good \\
\hline Bohacek 2012 & Yes & Yes & NR & Yes & Yes & Yes & Yes & Yes & Yes & No & Yes & NR & Yes & Yes & Good \\
\hline Bongiovanni 2012 & Yes & Yes & NR & Yes & Yes & Yes & Yes & Yes & Yes & No & No & NR & Yes & Yes & Fair \\
\hline Cristo 2016 & Yes & Yes & NR & Yes & No & Yes & Yes & Yes & Yes & No & Yes & NR & Yes & Yes & Good \\
\hline Faquin 2016 & Yes & Yes & NR & Yes & Yes & Yes & Yes & Yes & Yes & No & No & NR & Yes & Yes & Fair \\
\hline Guney 2017 & Yes & Yes & NR & Yes & Yes & Yes & Yes & Yes & Yes & No & Yes & NR & Yes & Yes & Good \\
\hline Guo 2017 & Yes & Yes & NR & Yes & No & Yes & Yes & Yes & Yes & No & Yes & NR & Yes & Yes & Fair \\
\hline Jo 2010 & Yes & Yes & NR & Yes & Yes & Yes & Yes & Yes & Yes & No & Yes & NR & Yes & Yes & Good \\
\hline Krauss 2016 & Yes & Yes & NR & Yes & Yes & Yes & Yes & Yes & Yes & No & Yes & NR & Yes & Yes & Good \\
\hline Nayar 2009 & Yes & Yes & NR & Yes & Yes & Yes & Yes & Yes & Yes & No & Yes & NR & Yes & Yes & Good \\
\hline Olson 2013 & Yes & Yes & NR & Yes & Yes & Yes & Yes & Yes & Yes & No & Yes & NR & Yes & Yes & Good \\
\hline Paajanen 2017 & Yes & Yes & NR & Yes & No & Yes & Yes & Yes & Yes & No & Yes & NR & Yes & Yes & Fair \\
\hline Renshaw 2010 & Yes & Yes & NR & Yes & Yes & Yes & Yes & Yes & Yes & No & No & NR & Yes & Yes & Fair \\
\hline Sullivan 2014 & Yes & Yes & NR & Yes & Yes & Yes & Yes & Yes & Yes & No & Yes & NR & Yes & Yes & Good \\
\hline Tepeoglu 2014 & Yes & Yes & NR & Yes & No & Yes & Yes & Yes & Yes & No & Yes & NR & Yes & Yes & Fair \\
\hline Theoharis 2009 & Yes & Yes & NR & Yes & Yes & Yes & Yes & Yes & Yes & No & Yes & NR & Yes & Yes & Good \\
\hline Ugurluoglu 2015 & Yes & Yes & NR & Yes & Yes & Yes & Yes & Yes & Yes & No & Yes & NR & Yes & Yes & Good \\
\hline Wu 2007 & Yes & Yes & NR & Yes & Yes & Yes & Yes & Yes & Yes & No & Yes & NR & Yes & Yes & Good \\
\hline Wu 2012 & Yes & Yes & NR & Yes & Yes & Yes & Yes & Yes & Yes & No & Yes & NR & Yes & Yes & Good \\
\hline Yang 2007 & Yes & Yes & NR & Yes & Yes & Yes & Yes & Yes & Yes & No & Yes & NR & Yes & Yes & Good \\
\hline Yassa 2007 & Yes & Yes & NR & Yes & Yes & Yes & Yes & Yes & Yes & No & Yes & NR & Yes & Yes & Good \\
\hline Zhou 2018 & Yes & Yes & NR & Yes & Yes & Yes & Yes & Yes & Yes & No & Yes & NR & Yes & Yes & Good \\
\hline Alabdulqader 2015 & Yes & Yes & NR & Yes & No & Yes & Yes & Yes & Yes & No & Yes & NR & Yes & Yes & Fair \\
\hline Al-Abbadi 2013 & Yes & Yes & NR & Yes & No & Yes & Yes & Yes & Yes & No & Yes & NR & Yes & Yes & Fair \\
\hline Al Dawish 2017 & Yes & Yes & NR & Yes & Yes & Yes & Yes & Yes & Yes & No & Yes & NR & Yes & Yes & Good \\
\hline Arul 2015 & Yes & Yes & NR & Yes & No & Yes & Yes & Yes & Yes & No & Yes & NR & Yes & Yes & Fair \\
\hline Bhartiya 2016 & Yes & Yes & NR & Yes & No & Yes & Yes & Yes & Yes & No & Yes & NR & Yes & Yes & Fair \\
\hline Bychkov 2018 & Yes & Yes & NR & Yes & Yes & Yes & Yes & Yes & Yes & No & No & NR & Yes & Yes & Good \\
\hline Kannan 2017 & Yes & Yes & NR & Yes & No & Yes & Yes & Yes & Yes & No & No & NR & Yes & Yes & Poor \\
\hline Kim 2011 & Yes & Yes & NR & Yes & No & Yes & Yes & Yes & Yes & No & Yes & NR & Yes & Yes & Fair \\
\hline Kim 2017 & Yes & Yes & NR & Yes & Yes & Yes & Yes & Yes & Yes & No & Yes & NR & Yes & Yes & Good \\
\hline Kim 2018 & Yes & Yes & NR & Yes & Yes & Yes & Yes & Yes & Yes & No & Yes & NR & Yes & Yes & Good \\
\hline Lee 2017 & Yes & Yes & NR & Yes & Yes & Yes & Yes & Yes & Yes & No & No & NR & Yes & Yes & Fair \\
\hline Limlunjakorn 2017 & Yes & Yes & NR & Yes & Yes & Yes & Yes & Yes & Yes & No & Yes & NR & Yes & Yes & Good \\
\hline Liu 2017 & Yes & Yes & NR & Yes & Yes & Yes & Yes & Yes & Yes & No & No & NR & Yes & Yes & Fair \\
\hline Mahajan 2017 & Yes & Yes & NR & Yes & Yes & Yes & Yes & Yes & Yes & No & No & NR & Yes & Yes & Fair \\
\hline Mehra 2015 & Yes & Yes & NR & Yes & No & Yes & Yes & Yes & Yes & No & Yes & NR & Yes & Yes & Fair \\
\hline Mondal 2013 & Yes & Yes & NR & Yes & Yes & Yes & Yes & Yes & Yes & No & Yes & NR & Yes & Yes & Good \\
\hline Mufti 2012 & Yes & Yes & NR & Yes & No & Yes & Yes & Yes & Yes & No & Yes & NR & Yes & Yes & Fair \\
\hline Naz 2014 & Yes & Yes & NR & Yes & No & Yes & Yes & Yes & Yes & No & Yes & NR & Yes & Yes & Fair \\
\hline Satoh 2017 & Yes & Yes & NR & Yes & Yes & Yes & Yes & Yes & Yes & No & Yes & NR & Yes & Yes & Good \\
\hline
\end{tabular}

